\title{
COMUNICAÇÃO INTERNA: ESTUDO DE CASO EM UMA EMPRESA DA ÁREA DA SAÚDE
}

\author{
Marcia Dayana Fernandes ${ }^{1}$ Cláudia Marcele de Campos² Flávio Bortolozzi $^{3}$ \\ ${ }^{1}$ Professora do curso de Bacharelado em Secretariado Executivo do Instituto Federal de Mato Grosso - IFMT \\ Mestranda do Programa de Mestrado Gestão do Conhecimento nas Organizações - Centro Universitário Cesumar - UNICESUMAR \\ marcia.fernandes@cba.ifmt.edu.br \\ ${ }^{2}$ Secretária Executiva do Instituto Federal de Mato Grosso - IFMT \\ Especialista em Proeja - IFMT. claudia.campos@ifmt.edu.br \\ ${ }^{3}$ Professor do Programa de Pós-graduação em Gestão do Conhecimento nas Organizações - UNICESUMAR. \\ flavio.bortolozzi@unicesumar.edu.br
}

\begin{abstract}
RESUMO
A comunicação interna da organização tem por objetivo fazer com que os colaboradores estejam bem informados, participativos, engajados e realizados com suas atividades tornando, assim, o ambiente de trabalho agradável e produtivo. Um programa de comunicação interna torna-se importante por possibilitar a criação de estratégias com o intuito de promover um ambiente mais organizado onde os colaboradores poderão concluir suas atividades com eficiência e conscientizando-se sobre como a comunicação está diretamente relacionada à produtividade. Dessa maneira, amenizam-se as falhas das informações gerando produtividade e, principalmente, assertividade. O objetivo principal deste estudo é propor uma estratégia de comunicação interna, para tanto, as medidas apresentadas buscaram a melhoria do ambiente de trabalho em todas as esferas de atuação dos colaboradores. Para atingir os objetivos, utilizou-se como metodologia a observação de campo e a condução de um questionário para evidenciar a situação da comunicação interna da empresa; também recorreu-se à bibliografia para embasamento da temática. Com o diagnóstico do problema apresentado à diretoria, essa se organizou para atender às sugestões e necessidades levantadas na pesquisa. Após a aplicação da metodologia da comunicação interna, os resultados apontaram uma operação de trabalho equilibrada, com ausência de conflitos das informações e, principalmente, melhoria no relacionamento interno e externo à empresa. A abordagem central sobre comunicação interna foi importante para a elaboração das atividades em equipe, fazendo com que todos reconhecessem a importância do trabalho em conjunto com uma comunicação clara e precisa, a fim de promover a sinergia para alcançar os resultados almejados.
\end{abstract}

PALAVRAS-CHAVE: Organização; Produtividade; Trabalho em equipe.

INTRODUÇÃO

O mundo corporativo, abrangente em sua concorrência, necessita manter sua reputação no mercado de atuação. Para isso, é importante alinhar seus processos de trabalho e, substancialmente, a comunicação interna para que esses processos sejam eficientes, pois falhas recorrentes poderão atingir os clientes e, como consequência, provocar o afastamento deles. Entretanto, as organizações podem melhorar seus produtos, seus serviços, seu atendimento, sua comunicação e a fidelização de seus clientes.

Com a melhoria da comunicação interna a empresa obterá benefícios, pois alcançará melhores níveis de qualidade dos serviços prestados, bem como um diferencial no atendimento aos seus clientes, obtendo, deste modo, o retorno esperado, ou seja, a lucratividade e o desenvolvimento da empresa. De acordo com Portela, Schumacher e Borth (2013, p.14), "a comunicação de qualidade é um dos grandes diferencias do mercado competitivo, mas tudo dependerá de como será utilizada".

A comunicação interna é uma área bastante difundida em vários vieses desde a gestão das relações humanas até as estratégias organizacionais, pois está associada a um fator comportamental e cultural não apenas para as organizações como também para o relacionamento interpessoal. Essa abordagem da comunicação, pode-se dizer, é um dos fatores mais importantes dentro de uma empresa, visto que através dela o conhecimento pode ser adquirido e repassado (CURVELLO, 2012).

É importante ressaltar que a comunicação interna objetiva o desenvolvimento e a implantação de estratégias organizacionais, sendo uma ferramenta complementar desde 
que alinhada aos objetivos e metas da empresa, gerando uma série de benefícios, como aprendizado, desenvolvimento, equilíbrio relacional, transparência das informações, processos de trabalho contínuo e, consequentemente, imagem positiva da organização no mercado de atuação (BUENO, 2015).

A principal motivação para o desenvolvimento desse tema ocorreu pela discussão da comunicação interna ser utilizada como estratégia organizacional. E a relevância dessa pesquisa justifica-se pela importância de manter os colaboradores bem informados para o desenvolvimento de suas atividades de forma correta, evitando o retrabalho, conflitos relacionais e consequências diretas com os clientes externos, levando, então, a atender ao objetivo geral desse trabalho que é propor um plano de ação para melhoria da comunicação interna na empresa pesquisada.

\section{MATERIAIS E MÉTODOS}

Para o desenvolvimento desse trabalho, foi realizada uma consultoria em uma empresa da área da saúde, precisamente uma clínica médica que prima pela excelência do atendimento aos pacientes (clientes). Para tanto, utilizou-se como metodologia o levantamento bibliográfico, conforme Gil (2002) a partir das publicações de vários autores disponíveis em livros e meios eletrônicos de revistas científicas da área, como: Robbins (1994) para o conceito de comunicação; Bueno (2003 e 2015) na comunicação estratégica; Lovelock e Wirtz (2006) na comunicação em relação a produtividade e desempenho; Kunsch (2003), Tomasi e Medeiros (2007 e 2010) na análise das práticas da comunicação interna, entre outros que contribuíram para embasar a temática.

De abordagem qualitativa, utilizou-se como instrumento para a coleta dos dados um questionário semiestruturado com 8 (oito) questões, conduzido para os 6 (seis) colaboradores da empresa, totalizando o universo da pesquisa. As questões fechadas foram direcionadas para identificar os níveis de percepção da comunicação interna, sendo divididas entre excelente, bom, neutro e ruim.

O resultado da pesquisa apontou fragilidades na comunicação interna, por isso, recorreu-se à observação de campo na empresa para propiciar o desenvolvimento do diagnóstico e a constatação da problemática, que encaminhou para o desenvolvimento de um plano de ação a fim de melhorar a comunicação interna como um todo.

\section{RESULTADOS E DISCUSSÕES}

\subsection{COMUNICAÇÃO EMPRESARIAL}

A comunicação entre duas pessoas é eficaz quando o ouvinte interpreta a mensagem de quem fala da forma que este pretendeu ser entendido. Na maioria das mensagens, podemos citar que 93\% delas são compreendidas por elementos não verbais, como posição do corpo, tom de voz e características físicas (ROBBINS, 1994).

A comunicação empresarial é extremante importante nas organizações devido se tratar de grandes grupos de pessoas que buscam lucros através de uma atividade, visando se destacarem uma entre as outras, diferentes e interdependentes dentro de um mesmo conjunto. De acordo com Portela, Schumacher e Borth (2013, p.14), "[...] a comunicação de qualidade é um dos grandes diferencias do mercado competitivo, mas tudo dependerá de como será utilizada".

Tomasi e Medeiros (2007) relatam que até os anos de 1970, nas organizações, a comunicação era tratada apenas como comunicação de negócios, com ênfase na habilidade dos interlocutores e na qualidade das mensagens escritas e orais. A partir dos anos 80, a comunicação passa a ser compreendida como discurso, pois devido à comunicação estar ligada ao comportamento humano, o discurso atua em um espaço 
entre ciência e arte, perpassando pela psicologia, sociologia, antropologia, filosofia, ética, linguística e semiótica. Na década de 90, a comunicação passa por uma nova abordagem, "[...] constituir-se em um processo integrado que orienta o relacionamento da empresa ou entidade com todos os seus públicos de interesse". (BUENO, 2003. p. 7). Desde então, a comunicação é compreendida como uma estratégia para as organizações. Assim, a comunicação estratégica nas organizações objetiva "[...] abrir os canais de comunicação entre a organização e seus públicos, em busca de confiança mútua, construindo a credibilidade e valorizando a dimensão social da organização, enfatizando sua missão e seus propósitos e princípios". (KUNSCH, 2003, p. 103).

Algumas características na comunicação representam benefícios dentro do conjunto organizacional, pois uma boa comunicação dentro da empresa não só evita rumores, fofocas e informações desencontradas como também abre espaço para dúvidas e sugestões, além de fazer o colaborador ter o sentimento de pertencimento ao contribuir, participar. No âmbito da produtividade, a comunicação aumenta o alinhamento da equipe evitando erros e retrabalho, e consequentemente, economia de recursos, de tempo, além de proporcionar uma imagem positiva da empresa. Convém ressaltar que segundo Lovelock e Wirtz (2006, p. 105), "Comunicações internas eficazes podem ajudar a assegurar entrega de serviço eficiente e satisfatório, conseguir relacionamentos de trabalho produtivos e harmoniosos e desenvolver confiança, respeito e fidelidade entre funcionários".

Entretanto, quando abordado o tema comunicação, é preciso identificar que não se trata apenas do ato de falar ou passar informações, a comunicação está em diversos elementos que podem ser codificados, ou seja, interpretados.

Comunicar bem não é só transmitir ou só receber bem uma informação. Comunicação é troca de entendimento e sentimento, e ninguém entende outra pessoa sem considerar, além das palavras, as emoções e a situação em que fazemos a tentativa de tornar comuns conhecimentos, ideias, instruções ou qualquer outra mensagem, seja ela verbal, escrita ou corporal (MATOS, 2009, p. 2).

Devido a esses fatores relevantes sobre a comunicação, fica claro que comunicar não é apenas passar uma informação mas também compreender seus significados. É ainda um dos meios mais importantes dentro da organização, pois uma informação dentro dela não poderá jamais ser de forma desarticulada e caótica, e sim, de forma organizada e coerente, seguindo uma linha de hierarquia de cargos e funções. Assim, todas as informações recebidas são processadas automaticamente, selecionadas e organizadas de acordo com o que a pessoa pensa e interpreta, por isso, faz-se necessário enviar a mensagem corretamente e certificar-se de que o outro a compreendeu.

A comunicação está diretamente ligada ao contexto da informação, que são dados relevantes e com um significado; exige análise para atribuir um contexto e, necessariamente, exige a mediação humana, ou seja, o colaborador que está como responsável pela comunicação direta (DAVENPORT; PRUSAK, 1998). Ainda de acordo com esses autores, a informação organizada e com um significado dentro de um contexto passa a ser concebida como conhecimento, percebe-se, dessa forma, o valor da comunicação (DAVENPORT; PRUSAK, 1998).

A comunicação interna coloca os seus colaboradores como parceiros, uma vez que quanto mais bem informados, mais engajados estarão com a missão da empresa. $\mathrm{E}$ estes, conscientes da importância que o seu trabalho representa na empresa, melhor desempenho terão, promovendo a eficácia organizacional (LEITE, 2006).

Através da comunicação é possível identificar uma sequência de fatores tanto positivos como negativos dentro da organização. Para alcançar uma comunicação de qualidade, alguns princípios básicos de entendimento e persuasão devem ser 
considerados. Assim, Tomasi e Medeiros (2010) demonstram três formas de analisar a relação da comunicação com a organização, a saber: a contenção, a produção e a equivalência.

\begin{abstract}
A contenção considera a comunicação como algo localizado dentro de uma estrutura organizacional material. Se uma estrutura não funciona, a organização desaba. A produção examina o modo como as organizações produzem comunicação, ou a comunicação produz a organização. Nesse caso, as organizações deixam de ser recipientes dentro dos quais as comunicações se estabelecem. A terceira abordagem trata a comunicação e a organização como uma entidade só. Assim, a comunicação é organização e organização é comunicação. (TOMASI; MEDEIROS, 2010, p. 30).
\end{abstract}

No exposto, existe uma linearidade entre os meios da comunicação organizacional, sendo considerado como modelo estratégico, pois o sucesso da estratégia de comunicação depende de um sólido desempenho da gestão para apoiar e alinhar aos objetivos da missão e visão da empresa (ARGENTI, 2006). Portanto, através da comunicação é possível obter um bom funcionamento tanto em termos operacionais como corporativos, gerando um bom trabalho de forma conjunta e alinhada, seguindo todos os objetivos da empresa no que se resume em fazer com que os colaboradores se tornem e se sintam pertencentes e presentes, obtendo benefícios como aumento no desempenho, geração e inovação de ideias de melhorias para empresa. Ressalta-se que, com essa proposta, é possível gerar pessoas mais envolvidas em desempenhar suas atividades com excelência e eficácia, criando defensores da marca organizacional (LOVELOCK; WIRTZ, 2006).

\title{
3.1.1 Barreiras na Comunicação
}

No contexto das organizações, a comunicação às vezes não atinge totalmente os objetivos por conta dos fatores que interferem no processo, pois qualquer ruído, ou seja, elemento que confunda, interfira ou perturbe a comunicação, fatalmente influenciará o resultado. Por esse motivo, essas barreiras precisam ser identificadas e corrigidas. "É possível minimizar essas dificuldades, corrigindo esses problemas, construindo uma comunicação sadia e transparente. Para tanto, a empresa deve investir, identificando e sanando as falhas e lacunas existentes." (LEMES, 2012, p. 35).

Um fator que se torna preocupante nas organizações é a situação gerada pelo ruído da comunicação, algumas vezes ocasionado pelas pessoas que criam barreiras entre elas, tornando-se negativo quando leva um colaborador a seguir a estagnação e a repetição de comportamentos. O quadro 01 exemplifica os tipos de barreiras mais comuns ocasionados na comunicação.

Quadro 1: Barreiras na comunicação

\begin{tabular}{|c|c|c|}
\hline Barreiras Humanas & Barreiras Físicas & Barreiras Semânticas \\
\hline Limitações pessoais & Espaço físico & $\begin{array}{c}\text { Interpretação de } \\
\text { palavras }\end{array}$ \\
\hline Hábitos de ouvir & Distância & $\begin{array}{l}\text { Translação de } \\
\text { linguagem }\end{array}$ \\
\hline Emoções & Interferências físicas & Significado de sinais \\
\hline Preocupações & Falhas mecânicas & $\begin{array}{l}\text { Significado dos } \\
\text { símbolos }\end{array}$ \\
\hline
\end{tabular}




\begin{tabular}{|c|c|c|}
\hline Sentimentos pessoais & Ruídos ambientais & Decodificação de gestos \\
\hline Motivações & Ocorrências locais & Sentido das lembranças \\
\hline
\end{tabular}

Fonte: Portela, Schumacher, Brauer (2015, p.18)

As barreiras de comunicação, uma vez identificadas, tornam a comunicação entre o emissor e o receptor no mesmo nível tanto nas relações interpessoais quanto nas pessoas que estão envolvidas para receber a informação. Segundo Robbins (1994), é importante avaliar a fonte de onde vem a informação, seja de uma pessoa, de um documento, de reportagens, artigos, é sempre válido checar para não passar uma informação incorreta. É importante também saber que as pessoas possuem percepções diferentes umas das outras, cada uma tem sua maneira de pensar, agir e se expressar.

\subsubsection{Práticas e Ferramentas da Comunicação Interna}

Conforme exposto, a comunicação interna é de suma importância porque equilibra o relacionamento entre os colaboradores e eleva a qualidade do funcionamento dos processos de trabalho, proporcionando um clima organizacional harmonioso e, em consequência, uma boa imagem da empresa perante os seus clientes. Segundo Tomasi e Medeiros (2010), a comunicação precisa respeitar o organograma hierárquico, caminhando por um sistema de redes e de fluxos internos e que podem ser: vertical ascendente, vertical descendente e horizontal.

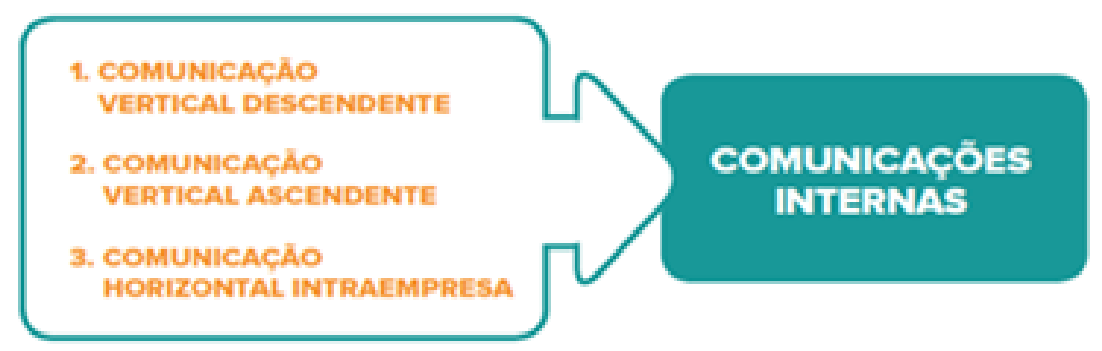

Figura 1: Tipos de Comunicação Interna

Fonte: Tomasi e Medeiros (2010) adaptado

Para os autores, a comunicação descendente é o processo de informações da cúpula diretiva da organização para os subordinados, isto é, dos níveis superiores aos inferiores. Utilizada para fornecer instruções, atribuir atividades e informações aos colaboradores, bem como identificar conflitos e ajudar a desenvolver as soluções. Assim, os autores relatam que a comunicação descendente, entre diretoria e gerência, apresenta melhor eficácia do que as comunicações entre gerência e chefes subordinados.

Nesse fluxo, a comunicação ocorre formalmente, porém com informações ou conteúdos massivos congestionando os canais. Em concordância, Torquato (2002) afirma que os canais devem ser priorizados em suas mensagens a fim de evitar a massificação, pois a comunicação descendente possui característica operacional de uso imediato, portanto deve ser repassada.

A comunicação ascendente é o inverso do fluxo descendente, isto é, dos níveis inferiores para os níveis superiores. É um feedback das estratégias propostas pela direção, assim, serve para avaliar os resultados, controlar e reorganizar processos, servindo de base para as decisões pois permite uma visão global das atividades colocadas em prática (TORQUATO, 2002).

A comunicação horizontal, também conhecida como comunicação lateral ou entre pares, estabelece a troca de informações ou orientações entre pessoas do mesmo nível hierárquico pois possuem forte relevância de conhecimento e poder para a sistematização 
e uniformização de ideias. Ainda nesse fluxo, é possível identificar a comunicação diagonal, ocorrida entre níveis de departamentos diferentes, isto é, o gerente de um departamento com um subordinado de outro departamento. Isso ocorre em organizações pouco burocráticas e com maior abertura de comunicação interna (TOMASI; MEDEIROS, 2010).

Para iniciar um planejamento de comunicação, a organização necessita identificar seu público, além de definir o que deseja da comunicação interna e o que é essencial para o desenvolvimento do trabalho. O planejamento comunicacional é o início de um trabalho constante e diário que a longo prazo poderá proporcionar resultados positivos e valores essenciais que permanecerão com a empresa (CLOSS, 2018).

Segundo Closs (2018, p. 10), "A escolha dos canais de comunicação que serão utilizados na sua estratégia de comunicação interna vai depender do perfil dos colaboradores, estrutura física e hierárquica da empresa, recursos disponíveis [...]". Durante o planejamento de comunicação interna, também é necessário identificar e definir os canais/ferramentas que serão utilizados de acordo com a finalidade e o contexto, conforme apresentado no quadro 2.

\section{QUADRO 2: Ferramentas da comunicação interna}

Murais: em formato de quadro, neles são divulgadas informações impressas. Apesar de serem um canal de comunicação antigo, ainda são bastante usuais. São instalados em locais estratégicos dentro da empresa, com informações curtas e objetivas, normalmente em corredores, para que todos os colaboradores possam visualizar.

Jornais e revistas impressos: possuem o formato tradicional de notícias, mas com menor número de páginas. O conteúdo pode se apresentar em textos e imagens, aproveitando o espaço disponível. Podem ser apresentadas notícias institucionais de comunicação interna e ou externa, seguir alguma temática sazonal entre outras informações que possam ficar disponíveis em longo prazo, ou seja, não se devem utilizar informações com data de validade para evitar o descarte de imediato.

Intranet: a intranet ou internet interna tem o objetivo de interligar unidades e departamentos com acesso exclusivo dos colaboradores através de uma rede corporativa. É utilizada também para o acervo digital da empresa pois todas as informações ficam armazenadas nos servidores.

Newsletter: é um recurso de comunicação digital com os colaboradores utilizada tanto para informar como para motivar os funcionários. Tendo uma periodicidade quinzenal, seu objetivo é destacar atividades desenvolvidas pelos colaboradores, como eventos internos, por exemplo.

E-mail Corporativo: forma de comunicação escrita, digital, com linguagem formal dentro do contexto organizacional. Utilizado também como fonte de informações e de checagem, pois acabam utilizando o e-mail como um armazenamento de arquivos e documentos.

Rede Social Corporativa: ferramenta que permite interação e contribuição de todos os colaboradores, o que favorece a comunicação horizontal, sendo que todos são emissores e receptores. Promove também a construção do conhecimento, pois aproxima diferentes áreas da organização.

Aplicativos - Apps: recurso mais recente no Brasil, os Apps tornaram a comunicação interna mais dinâmica. Existem diversos Apps com funcionalidades variadas que facilitam a comunicação interna e também externa. As organizações já contratam atendentes de Wattsapp para que possam atender seus clientes, sanar dúvidas, fazer o pós-vendas etc. Além disso, existem empresas de softwares que desenvolvem Apps nos moldes 
personalizados para cada empresa.

TV Corporativa: a proposta da TV corporativa é estabelecer a comunicação interna por meio de um canal exclusivo para os colaboradores. São exibidos vídeos institucionais, campanhas internas, avisos, além de promover a cultura organizacional. As telas são posicionadas em lugares específicos para atrair a atenção do colaborador.

Rádio Corporativa: a rádio corporativa, ou rádio interna, é um canal utilizado para realizar campanhas, divulgar notícias e informações de conhecimento geral, reforçar lembretes de treinamentos, datas e até mesmo para entretenimento. O canal é interessante para promover a comunicação com os colaboradores que trabalham em ambientes de fábrica, longe das telas, e as informações são colocadas no ar apenas quando necessário comunicar.

Fonte: Closs (2018) adaptado

Observa-se que cada canal de comunicação possui objetivos para a utilização e funcionalidade, alguns podem ser combinados para trabalhar em conjunto, manter as informações em sintonia e integração. O essencial no planejamento é ter, na organização, profissionais com habilidade e competência para desenvolver estratégias de comunicação interna e considerar quais canais serão mais adequados, pensando no contexto informacional e, principalmente, nos colaboradores, que são os receptores.

Para alcançar o objetivo geral desse trabalho, um questionário foi conduzido para os colaboradores e todos participaram. Os resultados apontaram, em concordância de $100 \%$ (cem), que a comunicação interna é um instrumento essencial para o desenvolvimento correto das atividades e, em contrapartida, 52\% (cinquenta e dois) dos colaboradores evidenciaram que a comunicação interna passa por problemas. De posse desses resultados, foi desenvolvido um plano de ação embasado na bibliografia apresentada, a fim de promover melhorias na comunicação interna da empresa onde foi realizada a consultoria.

O projeto foi criado para estabelecer uma melhoria da comunicação dentro da empresa visando facilitar o trabalho no cotidiano, melhorar o clima organizacional e a produtividade dos colaboradores. No projeto, foram apontados alguns elementos essenciais para a operacionalização da proposta:

1) Criação de um espaço para comunicação em que todos tenham a oportunidade de falar e sugerir ideias para um bom funcionamento de todo o conjunto laboral, facilitando, assim, a comunicação.

2) Realização de reuniões periódicas para que as informações sejam colocadas e que todos possam fazer perguntas e compartilhar preocupações sobre questões do cotidiano da organização. Com a inclusão de todos e a equipe poderá manter-se envolvida, fazendo com que os colaboradores tenham uma sensação maior de pertencimento dentro da organização refletindo em atividades positivas e satisfatórias.

3) Interação presencial e virtual com o uso de ferramentas como Skype e WhatsApp costumam ser mais eficientes em troca de perguntas e respostas rápidas. Porém, é importante ressaltar que a comunicação face a face tem um valor muito grande em termos de sinceridade e autenticidade, pois através da interação dentro de uma comunicação interna são elevados vários fatores positivos dentro de todo conjunto laboral. 
4) Feedback entre a equipe para dar oportunidade para que todos falem sobre questões cotidianas, como compartilhar seus sentimentos abertamente, evitando conversas paralelas dentro do ambiente de trabalho, buscando um ambiente mais harmonioso e equipes mais unidas em prol de resultados satisfatórios tanto para empresa como para os colaboradores. O feedback permite que a equipe se engaje mais em suas atividades, principalmente na questão de resolução de problemas ou sugestões de ideias com visão de ambiente mais satisfatório e equipe unida.

O projeto segue sequências importantes com base em pesquisas bibliográficas de como obter uma comunicação interna eficaz na organização. São pontos positivos que trazem benefícios no quesito clima organizacional, produtividade, criatividade, sensibilidade, incentivar trabalho em equipe e motivação. Primordialmente, as informações transmitidas dentro da empresa tenham alcance para todos os colaboradores envolvidos no contexto da mensagem e as informações devem ir e vir de forma clara e objetiva, dando voz, assim, às equipes para que possam também contribuir com ideias de melhorias e inovação dentro da organização.

Após a implantação do projeto de comunicação interna dentro da empresa, em avaliação recorrente da observação direta em busca dos novos resultados, constatou-se que as informações estavam sendo mais rápidas e precisas, de forma transparente e que o relacionamento entre a equipe e os gestores melhorou consideravelmente, uma vez que a comunicação interna eficaz tornou o ambiente organizacional equilibrado em suas relações e processos.

\section{CONCLUSÕES}

Os impactos causados pela comunicação interna dependerão de como as ferramentas para estabelecer uma comunicação eficaz serão utilizadas, pois uma estratégia de comunicação interna bem direcionada resultará em benefícios como a qualidade dos serviços prestados, clientes satisfeitos, crescimento e desenvolvimento da empresa (TOMASI; MEDEIROS, 2010); (PORTELA; SCHUMACHER; BORTH, 2013).

A partir do aporte teórico, buscou-se a compreensão da importância da comunicação interna nas organizações, bem como suas práticas e ferramentas para a operacionalização de forma estratégica. Por essa razão, o objetivo deste trabalho foi compreender como estava a questão da comunicação interna na clínica, sob a perspectiva dos colaboradores. Conforme exposto na bibliografia, com uma boa comunicação interna e diálogo entre os colaboradores é possível promover atividades produtivas e colaboradores participativos à organização.

A etapa do levantamento dos dados junto aos colaboradores da empresa foi de suma importância para desenvolver o diagnóstico e o plano de ação para sanar o problema apresentado, pois o resultado desse estudo apontou pontos negativos na comunicação interna da clínica.

Após a implantação do plano de ação, concluiu-se que para manter o equilíbrio das atividades laborais, bem como o relacionamento interpessoal positivo, faz-se necessário que, periodicamente, durante as reuniões, sejam analisados os processos de trabalho e se estão ocorrendo anomalias para que, então, seja revisto em comum diálogo com todos os envolvidos.

Ressalta-se que o objetivo da comunicação interna é promover um ambiente equilibrado e em sintonia com os objetivos organizacionais, visto que todas as ações e reações internas impactarão de alguma forma no ambiente externo, o que consolidará uma personalidade empresarial junto aos seus clientes. Desse modo, a construção de uma imagem positiva no mercado de atuação dependerá do uso da comunicação de forma correta quanto aos elementos do processo de comunicação e das ferramentas 
adequadas para que as informações e ou mensagens sejam circuladas sem ruídos ou transtornos, e que os gestores tenham em mente que o sucesso não depende apenas de recursos tecnológicos, depende, e muito, dos colaboradores internos, tornando-os aliados nos processos decisórios.

\section{REFERÊNCIAS}

BUENO, Wilson da Costa. Comunicação Empresarial: teoria e pesquisa. São Paulo: Manole, 2003.

Política de Comunicação: só poucas organizações podem ter. Comunicação empresarial, 2015.

CLOSS, Daniéli. Comunicação Interna: Tudo que você precisa saber para melhorar a da sua empresa. PROGIC, 2018. Disponível em: https://endomarketing.tv/comunicacaointerna/\#.XSVaAz9KjIU.

CURVELLO, João José Azevedo. Comunicação Interna e Cultura Organizacional. 2. ed. rev. e atual. - Brasília: Casa das Musas, 2012.

DAVENPORT, Thomas; PRUSAK, Laurence. Conhecimento Empresarial: como as organizações gerenciam o seu capital intelectual. Rio de Janeiro: Campus, 1998.

GIL, Antônio Carlos. Como elaborar projetos de pesquisa. 4. ed. São Paulo: Atlas, 2002.

KUNSCH, Margarida Maria Krohling. Planejamento de Relações Públicas na Comunicação Integrada. São Paulo: Summus, 2003.

LEITE, Quézia de Alcântara Guimarães. A importância da comunicação interna nas organizações. 2006.

Disponível

em:

<https://noticias.universia.com.br/destaque/noticia/2006/05/05/442402/importncia-da-

comunicao-interna-nas-organizaes.html.>

LEMES, Priscila dos Santos. A Importância da Comunicação Interna nas Organizações e suas Ferramentas. FEMA. ASSIS-SP: 2012. Disponível em:

< https://cepein.femanet.com.br/BDigital/arqTccs/0911261102.pdf>

LOVELOCK, Christopher; WIRTZ, Jochen. Marketing de Serviço: pessoas, tecnologia e resultado. São Paulo: Prentice Hall, 2006.

MATOS, Gustavo Gomes. Comunicação empresarial sem complicação: como facilitar a comunicação na empresa, pela via da cultura e do diálogo. São Paulo: Manole, 2009.

PORTELA, Keyla Christina Almeida; SCHUMACHER, José Alexandre; BORTH, Marcelo Rafael. Ferramentas do secretariado executivo. 2. ed. Cuiabá: Dos autores, 2013.

PORTELA, Keyla Christina Almeida; SCHUMACHER, Alexandre José, BRAUER, Karen Claudia Nin. Comunicação Institucional. Curitiba: Editora do Livro Técnico, 2015.

ROBBINS, Harvey A. Como Ouvir e Falar com Eficácia. Rio de Janeiro: Campus, 1994. 
TOMASI, Carolina; MEDEIROS, João Bosco. Comunicação Empresarial. São Paulo: Atlas, 2007.

Atlas, 2010.

Comunicação Empresarial. 3. ed. São Paulo:

TORQUATO, Gaudêncio. Cultura, poder, comunicação e imagem. 3ํ impressão. São Paulo: Pioneira Thomson Learning, 2002. 